\title{
Removal of hexavalent chromium by an aromatic alcohol
}

\author{
Ankita Basu, Rumpa Saha, Jayashree Mandal, Sumanta Ghosh, Bidyut Saha*
}

Bioremediation Lab, Department of Chemistry, the University of Burdwan, Golapbag, India;

Email: $\underline{\text { b saha31@rediffmail.com }}$

Received 17 May 2010; revised 21 May 2010; accepted 28 May 2010.

\begin{abstract}
$\mathrm{Cr}(\mathrm{VI})$ is a widespread environmental contaminant and a known human carcinogen. Biosorption is a very common method to remove toxic $\mathrm{Cr}(\mathrm{VI})$ from industrial waste water. In biosorption $\mathrm{Cr}(\mathrm{VI})$ is reduced to less toxic $\mathrm{Cr}$ (III) and adsorbed in biosorbent as $\mathrm{Cr}$ (III). Effective biosorbents contain hydroxy groups; it may be aliphatic or aromatic. Kinetics of reduction of $\mathrm{Cr}(\mathrm{VI})$ by an aromatic alcohol, benzyl alcohol, (which is an important volatile component of flowers of some night blooming plants) in micellar media have been studied spectrophotometrically. Micellar media is a probe to establish the mechanistic paths of reduction of $\mathrm{Cr}(\mathrm{VI})$ to $\mathrm{Cr}$ (III). Effects of electrolytes are studied to support the proposed reaction mechanism. Suitable surfactant $\&$ suitable concentration of electrolyte enhance the biosorption property.
\end{abstract}

Keywords: Biosorption; Carcinogen; Kinetics; Chromium (VI); Benzyl Alcohol; Non Functional Surfactants; Salt Effect

\section{INTRODUCTION}

Chromate $[\mathrm{Cr}(\mathrm{VI})]$ compounds are widely used in industry. Large amounts of toxic $\mathrm{Cr}(\mathrm{VI})$ are annually reintroduced into the environment through the discharge of chromium-containing industrial waste [1-4]. In the last few decades, the amount of chromium in aquatic and terrestrial eco-systems has increased a consequence of different human activities. Chromium is the new entry, after lead, cadmium and mercury in the major toxic metal series. In the Hinkley (a small desert town in San Bernardino Country, USA) case hexavalent chromium was used by Pacific Gas and Electric Company (PG \& E) in cooling systems to prevent pipes from rusting. The runoff of hexavalent chromium contaminated water on the PG \& E property, seeped into the ground and contaminated local water supplies. PG \& E was required to compensate the plaintiffs $\$ 333$ million, clean up the hexavalent chromium contamination, and stop using hexavalent chromium in their operation this is the highest amount of compensation in metal toxicity history. Various methods used for removal of $\mathrm{Cr}$ (VI) ions include chemical reduction and precipitation, reverse osmosis, ion exchange and adsorption on activated carbon or similar material [5]. But all these methods suffer from severe constraints, such as incomplete metal removal, high reagent or energy requirements, generation of toxic sludge or other waste products that require safe disposal. Some of the treatment methods involve high operating and maintenance cost. The high cost of the chemical reagents and the problems of secondary pollution also make the above physico-chemical methods rather limited in application. There is, therefore, a need for some alternative technique, which is efficient and cost-effective. The process of heavy metal removal by biological mate- rials is known as biosorption and the biological materials used are called biosorbents. Various biosorbents like bacteria, fungi, yeasts, agricultural by products, industrial wastes, etc have been used for biosorption. In this regard, considerable attention has been focused in recent years upon the field of biosorption for the removal of heavy metal ions from aqueous solutions [6]. Recently it is established that for chromium (VI) biosorption, chromium (VI) is first reduced to chromium (III) and then it is adsorbed as chromium (III) in the biosorbent [7]. Understanding of mechanism of chromium (VI) reduction to chromium (III) by some alcohol is important in this context. In this respect benzyl alcohol is ideal one. Benzyl alcohol is a volatile component of flower of a night blooming plant Gaura drummondii [8] and strawberry leaves [9]. The present investigations have been carried out in micro-heterogeneous systems to substantiate the proposed reaction mechanism as we carried out for other systems [10-17]. Effects of electrolytes are studied to support the proposed reaction mechanism.

\section{THEORETICAL}

It is expected that the reduction of $\mathrm{Cr}(\mathrm{VI})$ by benzyl al- 
cohol in aqueous surfactant media is proceed through normal oxidation mechanism by chromate ester. Benzyl alcohol is oxidized to benzaldehyde and $\mathrm{Cr}(\mathrm{VI})$ is reduced to $\mathrm{Cr}(\mathrm{IV})$. The over-all reaction can be written as:

$3 \mathrm{PhCH}_{2} \mathrm{OH}+2 \mathrm{HCrO}_{4}^{-}+8 \mathrm{H}^{+} \rightarrow 3 \mathrm{PhCHO}+2 \mathrm{Cr}(\mathrm{III})+$ $8 \mathrm{H}_{2} \mathrm{O}$.

\section{EXPERIMENTAL}

\subsection{Table for Materials and Reagents}

The materials and reagents are shown in Table 1.

\subsection{Procedure and Kinetic Measurements}

Under the kinetic conditions, solutions of the oxidant and mixtures containing the known quantities of the substrate(s) (i.e, benzyl alcohol) (under the conditions $[\mathrm{S}]_{\mathrm{T}}$ $\left.>[\mathrm{Cr}(\mathrm{VI})]_{\mathrm{T}}\right)$, acid and the other necessary chemi- cals were separately thermostated $\left( \pm 0.1^{\circ} \mathrm{C}\right)$. The reaction was initiated by mixing the requisite amounts of the oxidant with the reaction mixture. It is assumed that zero time was taken when half of the required volume of the oxidant solution had been added. The progress of the reaction was followed by monitoring the decay of oxidant $[\mathrm{Cr}(\mathrm{VI})]$ at $415 \mathrm{~nm}$ at different time intervals (2 minutes) with a UV-VIS spectrophotometer [UV-2450 (SHIMADZU)]. Quartz cuvettes of path length $1 \mathrm{~cm}$ were used. The observed pseudo-first-order rate con- stants $\left[k_{\text {obs }}\left(\mathrm{s}^{-1}\right)\right]$ were determined from the linear part of the plots of $\ln \left(\mathrm{A}_{415}\right)$ versus time $(\mathrm{t})$. Reproducible results giving first-order plots (co-relation co-efficient, $\mathrm{R}^{2} \geq 0.998$ ) were obtained for each reaction run. A large ex- cess $(\geq$ 15 -fold) of reductant was used in all kinetic runs. No interference due to other species at $415 \mathrm{~nm}$ was verified. Under the experimental conditions, the possibility of decomposition of the surfactants by $\mathrm{Cr}(\mathrm{VI})$ was inves-

Table 1. Materials and reagents.

\begin{tabular}{ll}
\hline Materials & Brand \\
\hline 1. Benzyl alcohol & AR, Merck, India \\
2. $\mathrm{K}_{2} \mathrm{Cr}_{2} \mathrm{O}_{7}$ & AR, BDH, India \\
3. $\mathrm{N}$-cetylpyridinium chloride (CPC) & AR, SRL, India \\
4. Sodium dodecylsulphate (SDS) & AR, SRL, India \\
5. $\mathrm{TX}-100$ & AR, SRL, India \\
6. $\mathrm{NaCl}$ & AR, Merck, India \\
7. $\mathrm{NH} \mathrm{Cl}_{4}$ & AR, Ranbaxy, India \\
\hline
\end{tabular}

tigated and the rate of decomposition in this path was found to be kinetically negligible.

\subsection{Product Analysis and Stoichiometry}

Under the kinetic condition benzyl alcohol is oxidized to benzaldehyde and estimation of the reaction products was carried by gravimetrically as 2, 4-dinitrophenyl hydrazone [18]. In a typical experimental set, $10 \mathrm{ml}$ of 0.06 mol dm${ }^{-3} \mathrm{Cr}(\mathrm{VI})$ in $1.0 \mathrm{~mol} \mathrm{dm}^{-3} \mathrm{H}_{2} \mathrm{SO}_{4}$ was added to 40 $\mathrm{ml}$ of $0.2 \mathrm{~mol} \mathrm{dm}^{-3}$ benzyl alcohol and the reaction was allowed to proceed to completion. Then the reaction mixture was added slowly with stirring to $60 \mathrm{ml}$ of a saturated solution of 2,4-dinitrophenyl hydrazine in 2.0 mol dm${ }^{-3} \mathrm{HCl}$. After storing for about $1 \mathrm{hr}$ in an ice-bath, the precipitate was collected weighed sintered glass crucible, washed with $2.0 \mathrm{~mol} \mathrm{dm}^{-3} \mathrm{HCl}$ followed by water and dried to a constant weight at $100-105^{\circ} \mathrm{C}$. The found ratio, $[\mathrm{Cr}(\mathrm{VI})]_{\mathrm{T}} /[\text { Carbonyl compound }]_{\mathrm{T}} \approx 2 / 3$ (from 3 independent determinations) supports the fol- lowing Stoichiometry.

$3 \mathrm{PhCH}_{2} \mathrm{OH}+2 \mathrm{HCrO}_{4}^{-}+8 \mathrm{H}^{+} \rightarrow 3 \mathrm{PhCHO}+2 \mathrm{Cr}(\mathrm{III})+8$ $\mathrm{H}_{2} \mathrm{O}$.

\section{RESULTS AND DISCUSSION}

\subsection{Dependence on $[\text { Substrate }]_{T}$ i.e, [Benzyl Alcohol] $_{T}$}

From the plot of $k_{\text {obs }}$ vs [benzyl alcohol $]_{\mathrm{T}}$, it is established that the path shows a first order dependency on $[\text { substrate }]_{\mathrm{T}}$ i.e, [benzyl alcohol $]_{\mathrm{T}}$ i.e., with increasing substrate concentration the rate of the reaction increases in a straight line manner. (Figure 1).

$$
\text { So, } k_{\mathrm{obs}}=k_{\mathrm{S}}[\mathrm{S}]_{\mathrm{T}}
$$

The above first order dependence on $[\mathrm{S}]_{\mathrm{T}}$ also maintained in the presence of surfactant like CPC, SDS, TX-100.

\subsection{Dependence on $\left[\mathrm{H}^{+}\right]$}

The acid dependence was followed in aqueous $\mathrm{HClO}_{4}$ media at fixed $\mathrm{Cr}(\mathrm{VI})$ and $[\mathrm{S}]_{\mathrm{T}}$. From the experimental fit (Figure 2), the observation is

$$
k_{\mathrm{obs}}=k_{\mathrm{H}}\left[\mathrm{H}^{+}\right]^{2}
$$

The above second order dependency is also maintained in the presence of surfactant (e.g, SDS).

\section{EFFECT OF SURFACTANTS}

\subsection{Effect of SDS}

Sodium dodecyl sulphate(SDS, a representative anionic surfactant) accelerate the reaction path. The plot of $k_{\mathrm{obs}}$ vs $[\mathrm{SDS}]_{\mathrm{T}}$ [Figure 3] shows a continuous increase up to the concentration of SDS. 


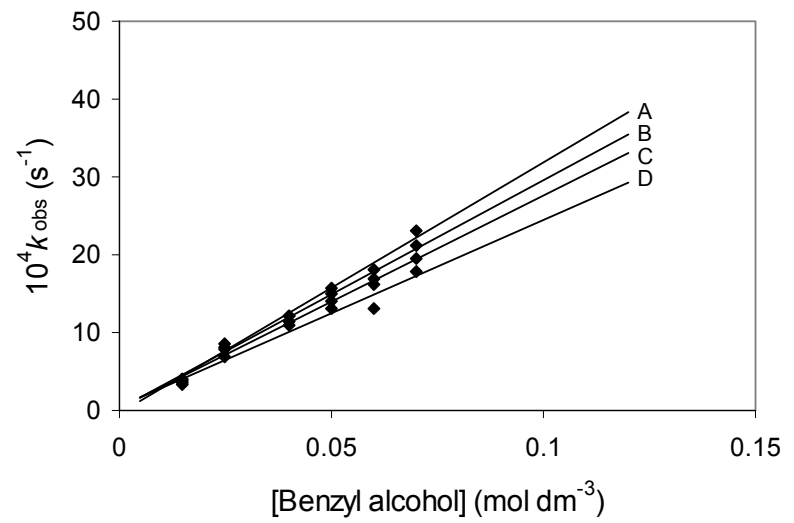

Figure 1. Dependence of $k_{\mathrm{obs}}$ on [benzyl alcohol] for the chromium (VI) oxidation of benzyl alcohol at $30^{\circ} \mathrm{C}$. $[\mathrm{Cr}(\mathrm{VI})]_{\mathrm{T}}=5 \times$ $10^{-4} \mathrm{~mol} \mathrm{dm}^{-3},\left[\mathrm{H}_{2} \mathrm{SO}_{4}\right]=0.25 \mathrm{~mol} \mathrm{dm}^{-3} \cdot \mathrm{A}\left([\mathrm{SDS}]_{\mathrm{T}}=2 \times 10^{-2}\right.$ $\left.\mathrm{mol} \mathrm{dm}{ }^{-3},[\mathrm{CPC}]_{\mathrm{T}}=0 \mathrm{~mol} \mathrm{dm}{ }^{-3},[\mathrm{TX}-100]_{\mathrm{T}}=0 \mathrm{~mol} \mathrm{dm}^{-3}\right)$, $\mathrm{B}\left([\mathrm{SDS}]_{\mathrm{T}}=0 \mathrm{~mol} \mathrm{dm}{ }^{-3},[\mathrm{CPC}]_{\mathrm{T}}=0 \mathrm{~mol} \mathrm{dm}^{-3},[\mathrm{TX}-100]_{\mathrm{T}}=2 \times\right.$ $\left.10^{-2} \mathrm{~mol} \mathrm{dm}^{-3}\right), \mathrm{C}\left([\mathrm{SDS}]_{\mathrm{T}}=0 \mathrm{~mol} \mathrm{dm}{ }^{-3},[\mathrm{CPC}]_{\mathrm{T}}=0 \mathrm{~mol} \mathrm{dm}^{-3}\right.$, $\left.[\mathrm{TX}-100]_{\mathrm{T}}=0 \mathrm{~mol} \mathrm{dm}^{-3}\right), \mathrm{D}\left([\mathrm{SDS}]_{\mathrm{T}}=0 \mathrm{~mol} \mathrm{dm}^{-3},[\mathrm{CPC}]=2 \times\right.$ $\left.10^{-3} \mathrm{~mol} \mathrm{dm}^{-3},[\mathrm{TX}-100]_{\mathrm{T}}=0 \mathrm{~mol} \mathrm{dm}{ }^{-3}\right)$.

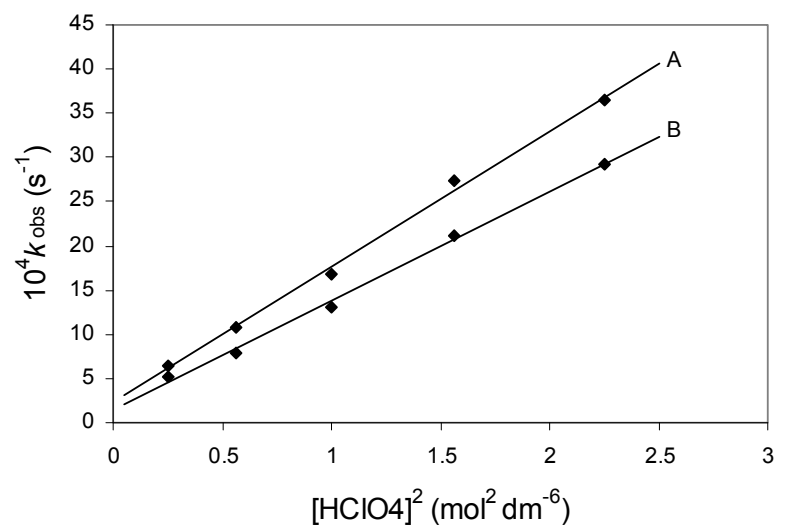

Figure 2. Dependence of $k_{\mathrm{obs}}$ on $\left[\mathrm{H}^{+}\right]$for the chromium(VI) oxidation of benzyl alcohol at $30^{\circ} \mathrm{C}$ in aqueous medium. $[\mathrm{Cr}(\mathrm{VI})]_{\mathrm{T}}=5 \times 10^{-4} \mathrm{~mol} \mathrm{dm}^{-3}$, [benzyl alcohol $]_{\mathrm{T}}=150 \times 10^{-4}$ $\mathrm{mol} \mathrm{dm}{ }^{-3},\left[\mathrm{H}_{2} \mathrm{SO}_{4}\right]=0.25 \mathrm{~mol} \mathrm{dm}^{-3} \cdot \mathrm{A}\left([\mathrm{SDS}]_{\mathrm{T}}=2 \times 10^{-2}\right)$, $\mathrm{B}\left([\mathrm{SDS}]_{\mathrm{T}}=0\right)$.

\subsection{Effect of CPC}

Cetyl Pyridinium Chloride (CPC, a representative cationic surfactant is found to retard the reaction path. Plot of $k_{\mathrm{obs}}$ vs $[\mathrm{CPC}]_{\mathrm{T}}$ [Figure 4] shows a continuous decrease and finally it tends to level off at higher concentration of CPC. The observation is identical to that observed by Bunton and Cerichelli [19] in the oxidation of ferrocene by ferric salt salts in the presence of cationic surfactant cetyl trimethyl ammonium bromide (CTAB).

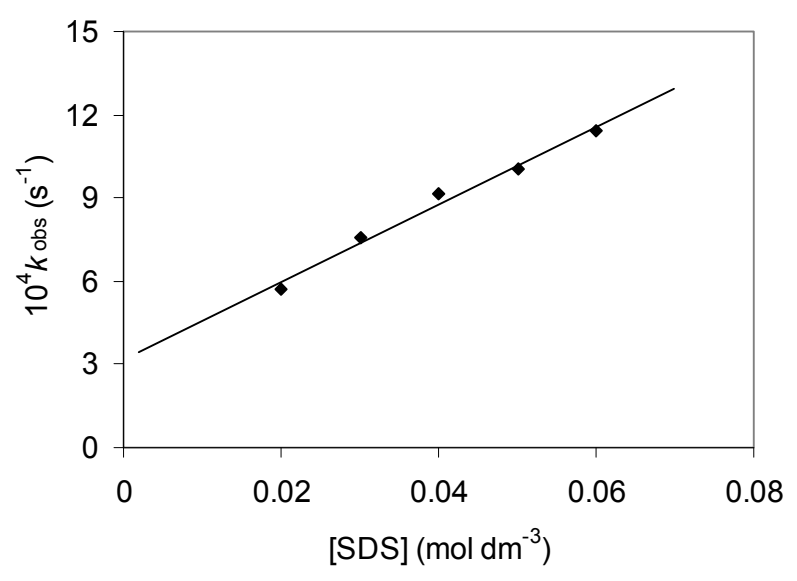

Figure 3. Dependence of $k_{\mathrm{obs}}$ on [SDS $]_{\mathrm{T}}$ for the chromium (VI) oxidation of benzyl alcohol at $30^{\circ} \mathrm{C}$. $[\mathrm{Cr}(\mathrm{VI})]_{\mathrm{T}}=5 \times 10^{-4} \mathrm{~mol}$ $\mathrm{dm}^{-3}$, [benzyl alcohol $]_{\mathrm{T}}=150 \times 10^{-4} \mathrm{~mol} \mathrm{dm}^{-3},\left[\mathrm{H}_{2} \mathrm{SO}_{4}\right]=0.25$ $\mathrm{mol} \mathrm{dm} \mathrm{m}^{-3}$.

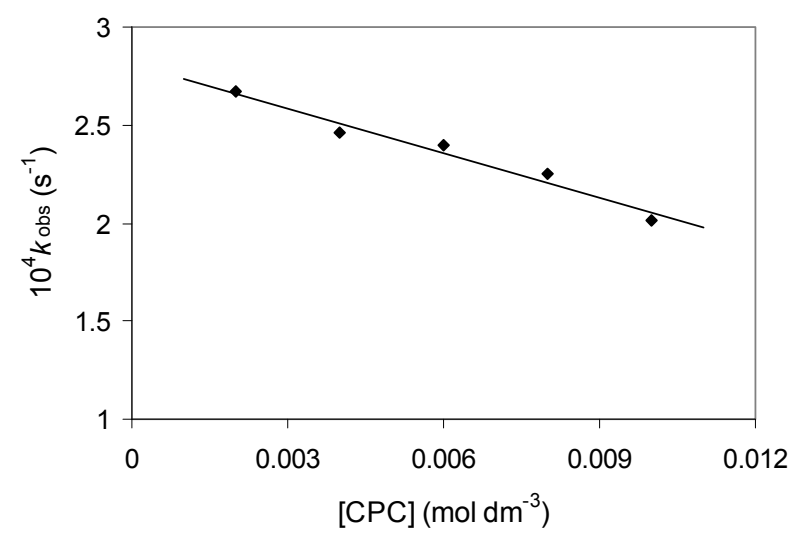

Figure 4. Dependence of $k_{\mathrm{obs}}$ on $[\mathrm{CPC}]_{\mathrm{T}}$ for the chromium(VI) oxidation of benzyl alcohol at $30^{\circ} \mathrm{C}$. $[\mathrm{Cr}(\mathrm{VI})]_{\mathrm{T}}=5 \times 10^{-4} \mathrm{~mol}$ $\mathrm{dm}^{-3}$, [benzyl alcohol $]_{\mathrm{T}}=150 \times 10^{-4} \mathrm{~mol} \mathrm{dm}{ }^{-3},\left[\mathrm{H}_{2} \mathrm{SO}_{4}\right]=0.25$ $\mathrm{mol} \mathrm{dm}{ }^{-3}$.

\subsection{Effect of $T X-100$}

Triton X-100(TX-100, a representative neutral surfactant) accelerates the reaction path. But the acceleration rate in TX-100 is less than that of SDS. The plot of $k_{\mathrm{obs}}$ vs $[\mathrm{TX}-100]_{\mathrm{T}}$ [Figure 5], shows a continuous increase up to the concentration of TX-100.

\subsection{Test for Acrylonitrile Polymerization}

Under the experimental conditions, the existence of free radical was indicated by polymerization of acrylonitrile under a nitrogen atmosphere.

\subsection{Mechanism and Interpretation}

Scheme 1 leads to the flowing rate law: 


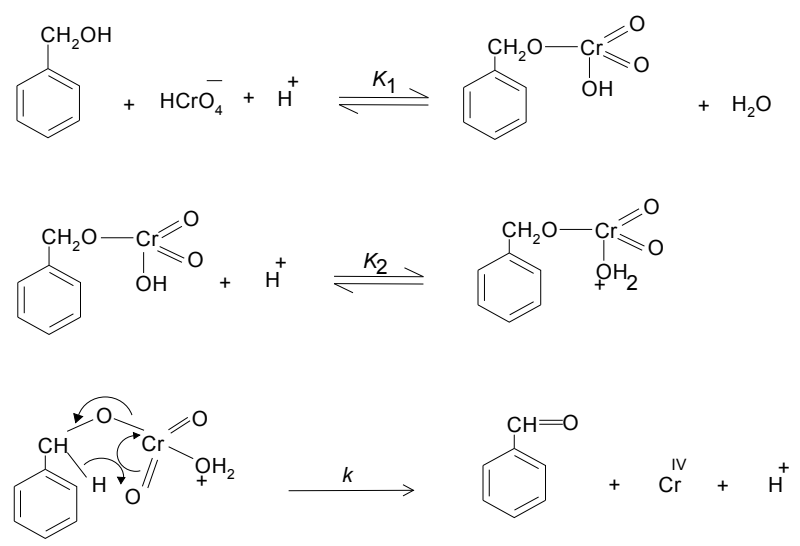

Scheme 1. Cr(Vl) reduction of Benzyl alcohol.

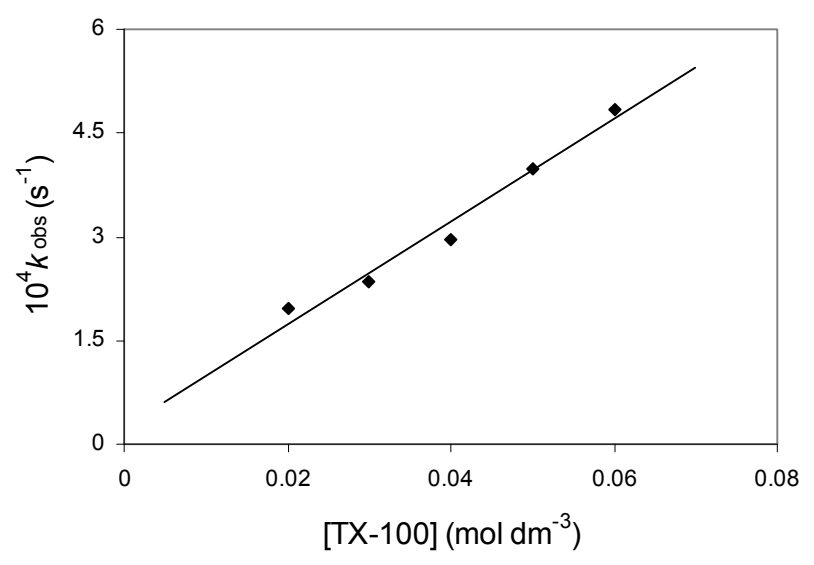

Figure 5. Dependence of $k_{\mathrm{obs}}$ on [TX-100] for the chro- mium (VI) oxidation of benzyl alcohol at $30^{\circ} \mathrm{C}$. $[\mathrm{Cr}(\mathrm{VI})]_{\mathrm{T}}=5 \times$ $10^{-4} \mathrm{~mol} \mathrm{dm}^{-3}$, [benzyl alcohol $]_{\mathrm{T}}=150 \times 10^{-4} \mathrm{~mol} \mathrm{dm}^{-3},\left[\mathrm{H}_{2} \mathrm{SO}_{4}\right]$ $=0.25 \mathrm{~mol} \mathrm{dm}^{-3}$.

$$
k_{\mathrm{obs}}=(2 / 3) k K_{1} K_{2}[\mathrm{~S}]_{\mathrm{T}}\left[\mathrm{H}^{+}\right]^{2}
$$

The pseudo-first-order rate constants $\left(k_{\mathrm{obs}}\right)$ in the presence of various concentrations of different types of surfactants, SDS (Sodium dodecyl sulfate, a representative anionic surfactant), CPC (N-cetyl pyridinium chloride, a representative anionic surfactant) and TX-100 (Trian $\mathrm{X}-100$, a neutral surfactant) are presented in Figures 4-6. The pseudo phase ion-exchange (PIE) [20] model is applied most widely in micellar catalysis. The basic assumption of the PIE is as follows:

1) Micelles act as a separate phase from water, all reactants are distributed quickly between water and micellar phase, and the reaction rate can be considered as the sum of that in two phases.

2) The reaction in the micellar pseudo phase occurs mainly at micelle surface.

3) The reactant ions and the inert ions compete at the charged micellar surface.
The data reveal that SDS and TX-100 accelerate the rate where as $\mathrm{CPC}$ decreases the rate. The rate acceleration is higher in the case of SDS than TX-100. This can be explained by Schemes 2 and 3 .

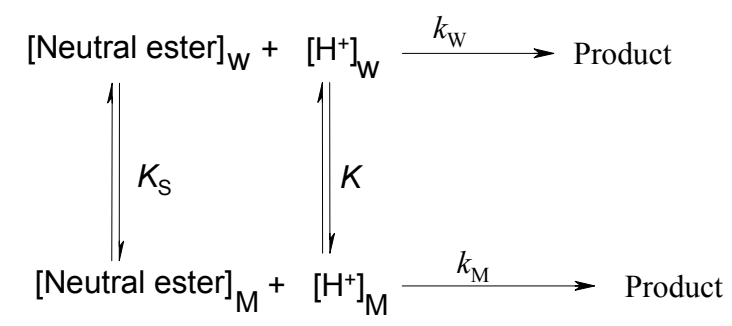

Scheme 2. Partitioning of the reactive species between the aqueous and micellar phases.

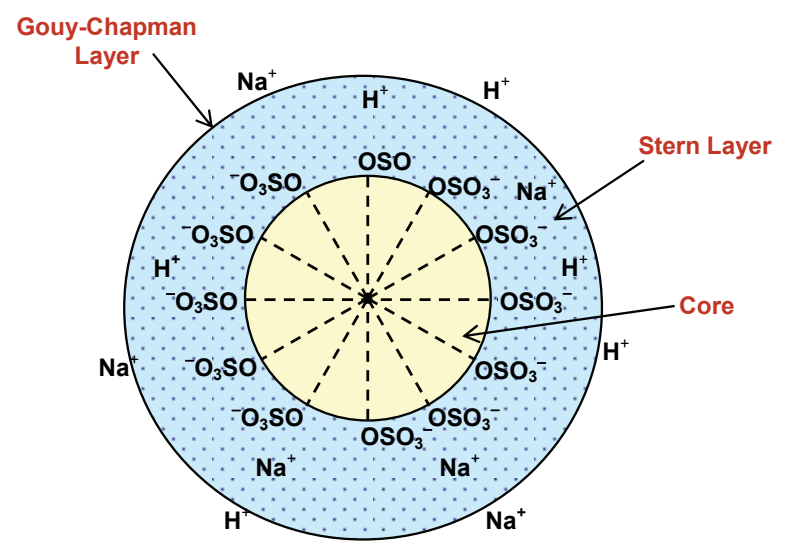

$\mathrm{OSO}_{3}{ }^{-}{ }^{-} \mathbf{C H}_{3}\left(\mathbf{C H}_{2}\right)_{11} \mathrm{OSO}_{3}{ }^{-} \mathrm{Na}^{+}$(SDS)

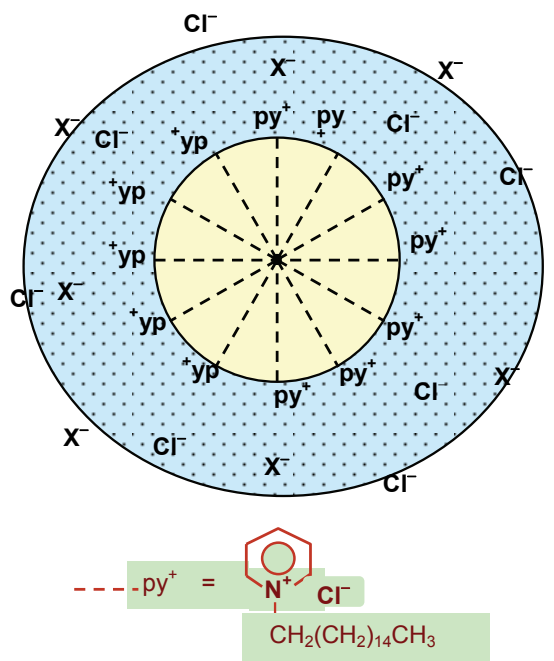

(CPC, i.e. hexadecylpyridinium chloride)

Scheme 3. Structural representation of anionic \& cationic surfactants. 
The formation of micelles by ionic surfactants is ascribed to a balance between hydrocarbon chain attraction and ionic repulsion. The net charge of micelles is less than the degree of micellar aggregates, indicating that a large fraction of counter ions remains associated with the micelle; these counter ions form the Stern layer at the micellar surface. For nonionic surfactants, however, the hydrocarbon chain attraction is opposed by the requirements of hydrophilic groups for hydration and space. Therefore, the micellar structure is determined by equilibrium between the repulsive forces among hydrophilic groups and the short-range attractive forces among hydrophobic groups. For bimolecular reactions inhibition arises from incorporation of one reactant into the micellar pseudo phase and exclusion of the other from it. $\mathrm{Ca}$ talysis is apparently caused, for the most part, by concentration of the two reactants into a small volume in the micellar Stern layer [21].

The substrate is partitioned in the Stern layer of the micellar phase. SDS being an anionic surfactant, owing to the electrostatic attraction between the positively charged $\left[\mathrm{H}^{+}\right]$species and negatively charged micellar head groups. $\left[\mathrm{H}^{+}\right]$easily attaches to the Stern layer of the micelle. The reaction takes place in both the micellar and aqueous media. The observed rate acceleration is due to the favored reaction in the micellar phase, where both $\mathrm{H}^{+}$ and the neutral ester are preferably accumulated. In the case of TX-100, $\mathrm{H}^{+}$also attaches to the Stern layer of the micelle, but the amount is less compared to SDS because TX-100 is a neutral surfactant, so no electrostatic attraction takes place. CPC is a cationic surfactant and consequently due to the electrostatic repulsion between the positively charged $\left[\mathrm{H}^{+}\right]$species and positively charged micellar head group, $\left[\mathrm{H}^{+}\right]$does not attaches to the Stern layer of micelle through the substrate. The reaction takes place only in aqueous media, which is depleted in the substrate concentration.

\subsection{Effect of Added Electrolyte}

Experimental evidence has shown that electrolyte inhibition of micellar catalysis is a general phenomenon [2224] with one apparent exception [25]. The proposed study has taken into consideration for better under standing of reduction mechanism. Electrolyte inhibition is rationalized by assuming that a counter ion competes with an ionic reagent (e.g., $\mathrm{OH}^{-}, \mathrm{H}_{3} \mathrm{O}^{+}$, and $\mathrm{X}^{-}$) for a site on the ionic micelle [26]. When $\mathrm{NH}_{4} \mathrm{Cl}$ is added the inhibition phenomena comes into play (Figure 7). But for the case of $\mathrm{NaCl}$ inhibition followed by enhancement takes place which is interesting (Figure 6). Enhancement of micellar catalysis by added salt is caused by their changing the shape or reducing the charge density

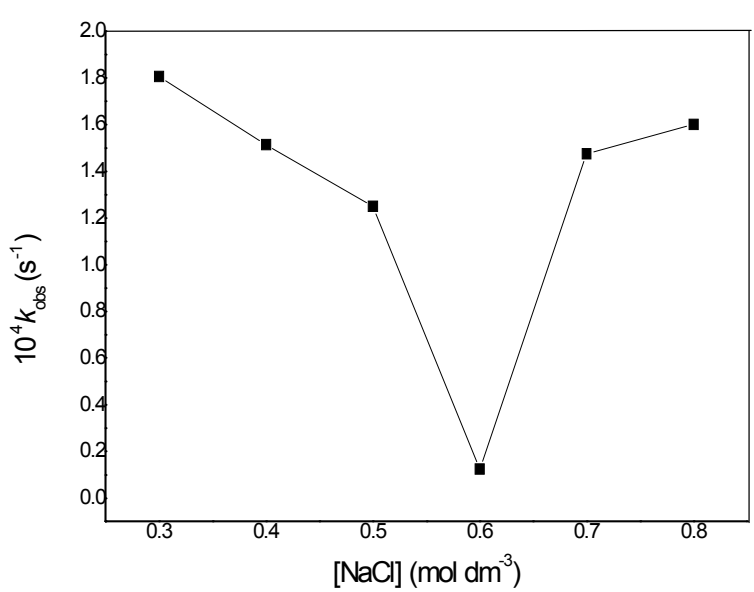

Figure 6. Dependence of $k_{\text {obs }}$ on [NaCl] for the chromium(VI) oxidation of benzyl alcohol at $30^{\circ} \mathrm{C}$ in SDS medium. $[\mathrm{Cr}(\mathrm{VI})]_{\mathrm{T}}$ $=5 \times 10^{-4} \mathrm{~mol} \mathrm{dm}{ }^{-3}$, [benzyl alcohol $]_{\mathrm{T}}=150 \times 10^{-4} \mathrm{~mol} \mathrm{dm} \mathrm{dm}^{-3}$, $\left[\mathrm{H}_{2} \mathrm{SO}_{4}\right]=0.25 \mathrm{~mol} \mathrm{dm}^{-3}$.

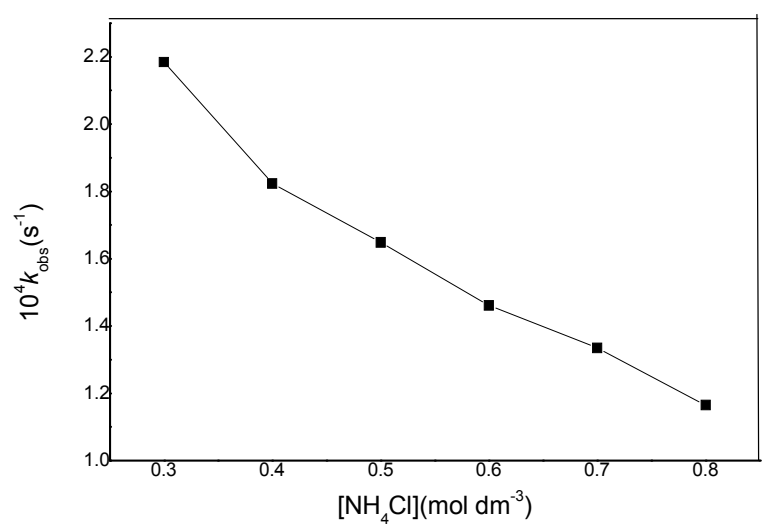

Figure 7. Dependence of $k_{\mathrm{obs}}$ on $\left[\mathrm{NH}_{4} \mathrm{Cl}\right]$ for the chromium(VI) oxidation of benzyl alcohol at $30^{\circ} \mathrm{C}$ in SDS medium. $[\mathrm{Cr}(\mathrm{VI})]_{\mathrm{T}}$ $=5 \times 10^{-4} \mathrm{~mol} \mathrm{dm}^{-3}$, [benzyl alcohol $]_{\mathrm{T}}=150 \times 10^{-4} \mathrm{~mol} \mathrm{dm}^{-3}$, $\left[\mathrm{H}_{2} \mathrm{SO}_{4}\right]=0.25 \mathrm{~mol} \mathrm{dm}^{-3}$.

of the micelle. Salts decrease the cmc (critical micelle concentration) and increase the aggregation no of ionic micelles [27-28] probably because increased screening by the counter ions decreases the effective charge density of the micelle.

\section{CONCLUSIONS}

Kinetics and mechanism of $\mathrm{Cr}(\mathrm{VI})$ reduction by benzyl alcohol in aqueous acid media have been studied under the conditions [benzyl alcohol $]_{\mathrm{T}}>>[\mathrm{Cr}(\mathrm{VI})]_{\mathrm{T}}$. under the kinetic conditions, the monomeric species of $\mathrm{Cr}(\mathrm{VI})$ has been found kinetically active. $\mathrm{Cr}(\mathrm{VI})$-substrate ester experiences a redox decomposition through $2 \mathrm{e}^{-}$transfer at 
Table 2. Presentation of rate constants values $\left(k_{\mathrm{obs}}\right)$ of benzyl alcohol oxidation in different surfactant medium.

\begin{tabular}{|c|c|c|c|c|c|c|}
\hline $\begin{array}{l}\text { [benzyl alcohol }]_{\mathrm{T}} \\
\left(\mathrm{mol} \mathrm{dm}^{-3}\right)\end{array}$ & $\underset{\left(\mathrm{mol} \mathrm{dm}^{-3}\right)}{[\mathbf{S D S}]_{\mathbf{T}}}$ & $10^{4} k_{\mathrm{obs}}\left(\mathrm{s}^{-1}\right)$ & $\underset{\left(\mathrm{mol} \mathrm{dm}^{-3}\right)}{[\mathbf{C P C}]_{\mathbf{T}}}$ & $10^{4} k_{\text {obs }}\left(s^{-1}\right)$ & $\begin{array}{l}{[\mathbf{T X}-\mathbf{1 0 0}]_{\mathbf{T}}} \\
(\mathrm{mol} \mathrm{dm}-3)\end{array}$ & $10^{4} k_{\mathrm{obs}}\left(\mathrm{s}^{-1}\right)$ \\
\hline $1500 \times 10^{-4}$ & 0.02 & $5.68 \pm 0.002$ & $0.002(\mathrm{M})$ & $2.668 \pm 0.001$ & 0.02 & $1.95 \pm 0.003$ \\
\hline $1500 \times 10^{-4}$ & 0.03 & $7.54 \pm 0.002$ & $0.004(\mathrm{M})$ & $2.46 \pm 0.002$ & 0.03 & $2.36 \pm 0.002$ \\
\hline $1500 \times 10^{-4}$ & 0.04 & $9.14 \pm 0.002$ & $0.006(\mathrm{M})$ & $2.395 \pm 0.001$ & 0.04 & $2.95 \pm 0.001$ \\
\hline $1500 \times 10^{-4}$ & 0.05 & $10.04 \pm 0.003$ & $0.008(\mathrm{M})$ & $2.25 \pm 0.001$ & 0.05 & $3.98 \pm 0.003$ \\
\hline $1500 \times 10^{-4}$ & 0.06 & $11.39 \pm 0.002$ & $0.01(\mathrm{M})$ & $2.013 \pm 0.002$ & 0.06 & $4.85 \pm 0.003$ \\
\hline
\end{tabular}

the rate determining step. The reaction shows both $1^{\text {st }}$ order dependency on [benzyl alcohol $]_{\mathrm{T}}$ and $[\mathrm{Cr}(\mathrm{VI})]_{\mathrm{T}}$ and $2^{\text {nd }}$ order dependency on $\left[\mathrm{H}^{+}\right]$ion. In the presence of some non-functional surfactants, the orders remain unchanged. CPC has been found to retard the rate while SDS and TX-100 shows the rate acceleration effect (Table 2). The effect of added electrolye gives different observations. Inhibition followed by enhancement is the effect of $\mathrm{NaCl}$ but for $\mathrm{NH}_{4} \mathrm{Cl}$ inhibition is the only fate. So for waste water treatment with biosorbent, SDS or TX-100 and suitable concentration of $\mathrm{NaCl}$ may be used for quick result.

\section{ACKNOWLEDGEMENTS}

Financial support from UGC, New Delhi is thankfully acknowledged.

\section{REFERENCES}

[1] Nriagu, J.O. and Nieboer, E., Eds. (1988) Chromium in the natural and human environments. Advances in Environmental Science and Technology. John Willey and Sons, New York, 20, 1-501.

[2] Sorahan, T., Burges, D.C., Hamilton, L. and Harrington, J.M. (1998) Lung cancer mortality in nickel/chromium plates. Occupational and Environmental Medicine, 55(4), 236-242.

[3] Mancuso, T.F. (1997) Chromium as an industrial carcinogen. American Journal of Industrial Medicine, 31(2), 129-139.

[4] Langardt, S. (1990) One hundred years of chromium and cancer: A review of epidemiological evidence and selected case reports. American Journal of Industrial Medicine, 17(2), 189-214.

[5] Ahluwalia, S.S. and Goyal, D. (2007) Microbial and plant derived biomass for removal of heavy metals from wastewater. Bioresource Technology, 98(12), 2243-2257.

[6] Volesky, B. and Holan, Z.R. (1995) Biosorption of heavy metals. Biotechnology Progress, 11(3), 235-250.

[7] Park, D., Yun, Y.S., Kim, J.Y. and Park, J.M. (2008) How to study $\mathrm{Cr}$ (VI) biosorption: Use of fermentation waste for detoxifying $\mathrm{Cr}$ (VI) in aqueous solution. Chemical Engineering Journal, 136, 173-179.

[8] Shaver, T.N., Lingren, P.D. and Marshall, H.F. (1997) Nighttime variation in volatile content of flowers of the night blooming plant, Gaum drummondii. Journal of Chemical Ecology, 23(12), 2673-2682.

[9] Nkpwatt, D.A., Krimm, U., Coiner, H.A., Schreiber, L. and Schwab, W. (2006) Plant volatiles can minimize the growth suppression of epiphytic bacteria by the phytopathogenic fungus Botrytis cinerea in co-culture experiments. Environmental and Experimental Botany, 56(1), 108-119.

[10] Das, A.K., Roy, A., Saha, B., Mohanty, R.K. and Das, M. (2001) Micellar effect on the reaction of Chromium (VI) oxidation of D-fructose in the presence and absence of picolinic acid in aqeous media: A kinetic study. Journal of Physical Organic Chemistry, 14(3), 333-342.

[11] Bayen, R., Islam, M., Saha, B. and Das, A.K. (2005) Oxidation of D-glucose in the presence of 2,2'-bipyridine by $\mathrm{Cr}^{\mathrm{VI}}$ in aqueous micellar media: a kinetic study. Carbohydrate Research, 340(13), 2163-2170.

[12] Islam, M., Saha, B. and Das, A.K. (2005) Kinetics and mechanism of 2,2'-bipyridyl and 1,10-phenanthrolinecatalysed chromium(VI) oxidation of d-fructose in aqueous micellar media. Journal of Molecular Catalysis A: Chemical, 236(1-2), 260-266.

[13] Islam, M., Saha, B. and Das, A.K. (2006) Chromic acid oxidation of hexitols in the presence of 2,2'-bipyridyl catalyst in aqueos micellar media: a kinetic study. International Journal of Chemical Kinetics, 38(9), 531-539.

[14] Islam, M., Saha, B. and Das, A.K. (2007) Kinetics and mechanism of picolinic acid promoted chromic acid oxidation of maleic acid in aqueous micellar media. Journal of Molecular Catalysis A: Chemical, 266(1-2), 21-30.

[15] Saha, B., Sarkar, S. and Choudhury, K.M. (2008) Micellar effect of quinquivalent vanadium ion oxidation of D-glucose in aqueous acid media: a kinetic study. International Journal of Chemical Kinetics, 40(5), 282-286.

[16] Choudhury, K.M., Mandal, J. and Saha, B. (2009) Micellar catalysis of Chromium (VI) oxidation of ethane-1, 2-diol in presence and absence of 2,2'-bipyridine in aqueos acid media. Journal of Coordination Chemistry, 62(11), 1871-1878.

[17] Ghosh, S.K., Basu, A., Paul, K.K. and Saha, B. (2009) Micelle catalyzed oxidation of propan-2-ol to acetone by penta-valent vanadium in aqueous acid media. Molecular Physics, 107(7), 615-619.

[18] Vogel, A.I. (1958) Elementary practical organic chemistry, Part-III, quantitative organic analysis, ELBS and Longman Group Ltd., London, p. 739.

[19] Bunton, C.A. and Cerichelli, G. (1980) Micellar effects 
upon electron transfer from ferrocenes. International Journal of Chemical Kinetics, 12(8), 519-533.

[20] Menger, F.M. and Portnoy, C.E. (1967) Chemistry of reactions proceeding inside molecular aggregates. Journal of the American Chemical Society, 89(18), 4698- 4703.

[21] Bunton, C.A. (1979) Reaction kinetics in aqueous surfactant solutions. Catalysis Reviews - Science and Engineering, 20(1), 1-56.

[22] Morawetz, H. (1969) Catalysis and inhibition in solutions of synthetic polymers and in micellar solutions. Advances in Catalysis \& Related Subjects, 20, 341-371.

[23] Cordes, E.M. and Dunlop, R.B. (1969) Kinetics of organic reactions in micellar systems. Accounts of Chemical Research, 2(11), 329-337.

[24] Fendler, E.J. and Fendler, J.H. (1971) Micellar catalysis in organic reactions: Kinetic and mechanistic implications. Advances in Physical Organic chemistry, 76, 271406.

[25] Bunton, C.A., Minch, M. and Sepulveda, L. (1971) Enhancement of micellar catalysis by added electrolyte. Journal of Physical Chemistry, 76(2), 2707-2709.

[26] Das, A.K. (2004) Micellar effect on the kinetics and mechanism of chromium (VI) oxidation of organic substrates. Coordination Chemistry Review, 248(1-2), 81-99.

[27] Mysels, K.J. and Princen, L.H. (1957) Light scattering by ideal colloidal electrolyte. Journal of Colloid Science, 12(6), 594-605.

[28] Shinoda, K. (1955) The critical micellar concentrations in aqueous solutions of potassium alkyl malonates. Journal of Physical Chemistry, 59(5), 432-435. 